\title{
Star dust: greetings from deep space
}

\author{
Hugo M. Ortner ${ }^{1}$
}

Received: 27 February 2016/Accepted: 3 June 2016/Published online: 14 June 2016

(C) Springer International Publishing Switzerland 2016

\begin{abstract}
Dust is an essential component throughout space. Interstellar dust is the solid phase of interstellar matter from which stars and planets form. Cometary dust is the most pristine material from the early solar nebula. Huge dust clouds are observable, e.g., with the renewed Hubble Space Telescope. Cosmic dust is also attracted by the earth's gravity and is deposited on the earth's surface in estimated quantities of 30-1000 $\mathrm{t}$ daily. Space exposed surfaces, e.g., of space stations or space vehicles may be seriously eroded by cosmic dust hitting these surfaces. This has been extensively studied by secondary ion mass spectrometry, the key instrumentation for cosmic dust analysis and dust eroded surfaces in combination with scanning electron microscopy. The significance of material degradation of space exposed surfaces has been studied by a "Long Duration Exposure Facility" experiment managed by NASA. Another serious problem is the great amount of debris from older space installations in near-Earth Space. Measures of respective mitigation are outlined. Important chapters, e.g., on the International Space Station (ISS) and the Hubble Space Telescope (HST) refer to new respective information available. A further chapter describes asteroids with much larger "grain sizes" than cosmic dust. The eminent danger upon impact of asteroids on the Earth is outlined for most recent incidents (Tunguska and Chelyabinsk). Exciting missions, such as the Star Dust Mission and the Rosetta Mission, are shortly outlined. Finally, the speed of light and the incredible dimensions of the universe are discussed. This leads to the conclusion that manned
\end{abstract}

Hugo M. Ortner

hugo.ortner@tnr.at

Osterbichl 16, 6600 Breitenwang, Tirol, Austria space travel is very dangerous for man, and restricted to just the nearer part of our planetary system.

Keywords Cosmic dust: its nature, significance, analytical, and morphological characterization - Chondrites and carbonaceous chondrites - Materials degradation of space exposed surfaces. The importance and characteristics of low earth orbits (LEOs) - Essential missions of man into space - The Long Duration Exposure Facility (LDEF) Experiment - The Hubble Space Telescope (HST) - The International Space Station (ISS) - Largeparticle space debris - Space debris mitigation measures . Asteroid incidents . The speed of light and the magnificence of the univers - The eminent dangers of space travel

\section{Introduction: meteorites and cosmic dust-relatively frequent visitors from the deep space on Earth}

It is estimated that more than $1000 \mathrm{t}$ of cosmic dust and some coarser rocky materials are reaching the surface of the earth daily! [1]. Another source reports daily that dust quantities of between 30 and $400 \mathrm{t}$ [2] are reaching the earth. Plane [3] lists a range of 2-300 t/day. It can be deduced from the great variation of these data that they are only rough estimates and they most likely also vary greatly on the time scale.

This admittedly sounds like the story of a Hollywood film-script, but it is a fact. However, larger particles or big rocks fortunately seldom reach the earth. The latest known case is the meteor of Chelyabinsk which had a diameter of about $19 \mathrm{~m}$.

Chelyabinsk is a city of around half a million inhabitants east of the Ural Mountains in Russia. The meteor had a 
weight of ca. $20,000 \mathrm{t}$ and exploded at a height of $30 \mathrm{~km}$ due to heating of its surface by friction. The meteor had a velocity of about $65,000 \mathrm{~km} / \mathrm{h}$ (which amounts to 50 times the velocity of sound in air). The airburst of the meteor which broke apart was about 20-30 times the explosion of the atomic bomb at Hiroshima [4]. It did not cause a greater catastrophe, but the pressure wave caused by the meteor broke hundreds of window glasses and also caused some broken or cracked walls in numerous buildings. Fortunately, such events occur very seldom. According to respective statistics of NASA and the ESA, impacts of meteorites which might form a crater of $20 \mathrm{~km}$ in diameter upon impact occur only every 100,000 years. In addition, the Space Agency traces all meteorides with diameters of $0.5 \mathrm{~km}$ or bigger [4].

Some explanations of terms frequently used in this paper should be given:

A "meteoride" is an object before it enters the earth's atmosphere.

A "meteor" is the visible phenomenon.

A "meteorite" is the remaining object that reaches the earth's surface.

An "asteroid" is a rocky, carbonaceous, or metallic body, smaller than a planet. Most asteroids have orbits in the Mars-to-Jupiter region [5, 6].

A "comet" is principally very similar to an asteroid. However, the latter had been formed nearer to the sun and, hence, contains less ice than comets. These are born far away from the sun and contain a lot of ice. Some scientists call them "dirty snowballs". They normally move in the outer realms of the solar system. If they approach the sun, the ice evaporates. Dust and rocky material of the nucleus of the comet form a long and often very impressive tail of the comet. If the comet comes near to the Earth, the smaller rocky material forms a multitude of shooting stars [2].

\section{Cosmic dust: an essential part of matter in the universe and the basis of the formation of our own solar system}

Interplanetary and interstellar dust or, generally, cosmic dust is an essential component throughout space. It constitutes an essential part of total matter of our universe. Interstellar dust is the solid phase of interstellar matter from which stars and planets form. Some of the cosmic dust particles stem from the solar nebula and might have formed 4.56 billion years ago when the solar system developed [5, 6]. Cometary dust is the most pristine material from the early solar nebula. Dusty planetary rings (e.g. of Saturn) are analogues of the interplanetary dust cloud in their own right $[6,7]$.
Our own solar system formed out of a huge cloud of gas and dust 4.56 billion years ago. The cloud densified under the influence of its own gravity. Since the cloud rotated, it was flattened by its centrifugal force and formed a disk. In its center, the sun was born and around it the planets, planetoids, and comets formed. Such systems had been formed in many places of the vast realms of the Milky Way [5].

\section{A first characterization of cosmic dust reaching the Earth}

Since the group of Chondrites is, by far, the most important class of micro-meteorites, it is discussed separately in "Chondrites". However, chondritic particles are not the only species of dust reaching the Earth. As will be mentioned in "The LDEF experiment", $\mathrm{Al}_{2} \mathrm{O}_{3}$ particles from former Soviet rocket fuels are still detected as well as debris particles from the paint on rockets, ash particles from great volcanic eruptions, and debris particles from human installations in near-Earth space, e.g., radioactive particles from the deliberately blown up small atomic reactors from early Russia space installations as well as particulate residuals of space toilets. Size distribution is generally in the range of 1 to $1000 \mu \mathrm{m}$. Most particles are in the single- $\mu \mathrm{m}$ range and up to $20 \mu \mathrm{m}$. They contain considerable amounts of aggregated sub- $\mu \mathrm{m}$ grains [7].

- The velocity range in space is between ca. 10-70 $\mathrm{km} \mathrm{s}^{-1}$. The particles are essentially slowed down in the atmosphere. Classification of their velocity is not found in the available literature.

Dust particles are travelling in space with velocities of at least $10 \mathrm{~km} / \mathrm{s}$. If they hit material surfaces, they almost completely evaporate due to their high impact velocity and cause the formation of a crater as will be discussed in more detail in "The significance of material degradation of space exposed surfaces".

Consequently, material degradation by micro-meteorites is one of the common phenomena space flights have to cope with. Some of the collected particles might be hundreds of million years old before they are trapped by the earth's gravity and settle to the earth's surface as will be described in "The study of cosmic dust".

Nevertheless, general literature on cosmic dust is scarce [7-10].

\section{Dust sources}

Since we have learned that dust is an essential component throughout space, the next question to discuss is about the origin of cosmic dust. There are several sources of it: 
- Explosion of Red Giants, their mass amounts to 0.3-8 times of the mass of our sun [2].

- Explosion of supernovae: these stars thereby loose a part of their matter into deep space in form of dust which forms huge clouds. Hence, they are the most important source of dust in the universe.

- Another source is the Belt of Asteroids situated between the orbits of Mars and Jupiter. There, the asteroids frequently collide with each other thereby generating dust and smaller particles [2-5].

- In addition, dust is formed by comets which are disintegrating when coming near to the sun [10].

- Last but not least, atomic and molecular aggregation can take place in the winds of stars. The tiny grains are travelling through space. Some of them might be destroyed again, but other ones might eventually travel to a large dust cloud, where they can contribute to the formation of planets, suns, etc., as described above [5].

\section{The star dust mission (NASA 2002-2006)}

In January 2006, the star dust mission successfully returned dust samples from the tail of comet $81 P / W i l d 2$. The dust grains have been analyzed by several US and European groups especially for $\mathrm{C}, \mathrm{N}$, and $\mathrm{O}$ isotopic compositions by NanoSIMS. Such samples contain isotopic memories of their pre-solar origin or of early solar systems processes. It was found that cometary matter is a diverse assemblage of pre-solar and solar system materials [11].

\section{Cosmic dust and meteorites: how do they arrive on the earth's surface?}

Some particles are trapped by the earth's gravity and enter its atmosphere. Cosmic dust particles are also frequently called interplanetary dust particles (IDPs). However, the term "cosmic dust particles" is retained here. Cosmic particles up to about $50 \mu \mathrm{m}$ can efficiently radiate away the heat which is generated by their slowing down in the atmosphere due to friction. Greater particles cannot do this effectively enough and, hence, burn up in the upper layers of the atmosphere, or explode in the lower atmosphere (cf. to the Chelyabinsk incident in the introductory chapter).

Depending on the atmospheric conditions (wind, weather), this part of the trip of small particles can last several months. They usually endure this travel relatively sound. This is the reason why our planet is gaining daily several tonnes (up to 1000) due to the trapping of extraterrestrial material. This weight gain is in part counterbalanced by a loss of hydrogen, helium, atomic oxygen, and possibly carbon (mainly as methane) in the exosphere as a result of non-thermal escape mechanisms $[4,7]$.

\section{The study of cosmic dust}

The two main methods used for the characterization of dust particles will be shortly mentioned.

\section{Morphology studies by scanning electron microscopy (SEM)}

The workhorse for all studies in the micrometer domain is the scanning electron microscope (SEM). All particle morphologies shown in this paper have been produced by SEM. The best and most intensive introduction to SEM and $\mathrm{X}$-ray microanalysis is the book of Goldstein et al. [12].

\section{Secondary ion mass spectrometry (SIMS): the key instrumentation for cosmic dust analysis}

An excellent and short introduction to SIMS is given in [13]. In addition, this article also provides an overview on "Ion Microprobe Isotopic Analysis on Ancient Stardust".

It is difficult to gain information on the nature of impacting particles due to the fact that most particles are evaporating during the impact. The minute amounts of particle matter which remain on the substrate surface in and around the impact crater can only be detected by the most sensitive method of the topochemical analysis: SIMS. In addition, the ability of SIMS to distinguish between various isotopes of an element is the key to differentiate between terrestrial and cosmic particles [10-15]. The outstanding significance of SIMS for such investigations consequently led to the development of the NanoSIMS with a dramatically improved lateral resolution in the $10 \mathrm{~nm}$ domain (as compared to a lateral resolution in the single- $\mu \mathrm{m}$ range for the conventional SIMS). It also has a multi-detection system which is important, since the amount of material to be sputtered is very limited in this special application [14-16].

\section{Problems with sampling of interplanetary dust}

The sampling and characterization of cosmic dust particles has developed to an intricate and fascinating area of cosmo-physics and cosmo-chemistry [10-15]. The seemingly simplest way-the direct collection of cosmic dust particles in space with a dedicated space exposed deviceis in practice problematic. The problem is the high velocity of several $\mathrm{km} / \mathrm{s}$ with which these particles travel. When they hit a collecting device without deceleration they almost completely evaporate in fractions of a second. A part of the evaporated material will condense around a 
crater which is formed upon the particle impact while only a minor fraction of the original projectile will survive the impact as debris inside the crater, Fig. 1.

An ideal collector for cosmic dust particles would gently decelerate the often fragile particles. This is exactly what happens in the outer realms of the earth's atmosphere as has already been mentioned in "Cosmic dust and meteorites: how do they arrive on the earth's surface?". Eventually, the particles are descending with quite low velocities. Interestingly, this also causes a density of cosmic particles in the earth's atmosphere that is many orders of magnitude higher than in space. To prevent a mixing of cosmic particles with terrestrial aerosols, the sampling has to be carried out in the stratosphere. In the 1960s, it was tried to collect cosmic dust with high flying balloons. However, the yield was very modest. Therefore, NASA initiated a program in the 1970 s, in which cosmic dust was collected with U2-planes flying in the stratosphere [10]. For this purpose, palm-sized collecting surfaces had been prepared which were coated with silicon oil. These collecting surfaces were exposed to the air stream of the planes travelling at an altitude of $20 \mathrm{~km}$ (twice as high as most commercial traffic) beneath a wing of the plane for several hours. Nevertheless, only a single particle greater than $5 \mu \mathrm{m}$ is caught per hour. Of these, a very few collected particles in the clean surroundings every second particle is still of terrestrial origin. Often, ash particles from volcanic eruptions are found which had been spewed into the atmosphere. Hence, after greater volcanic eruptions (as, e.g., of the Pinatubo in 1991), the collection of cosmic dust

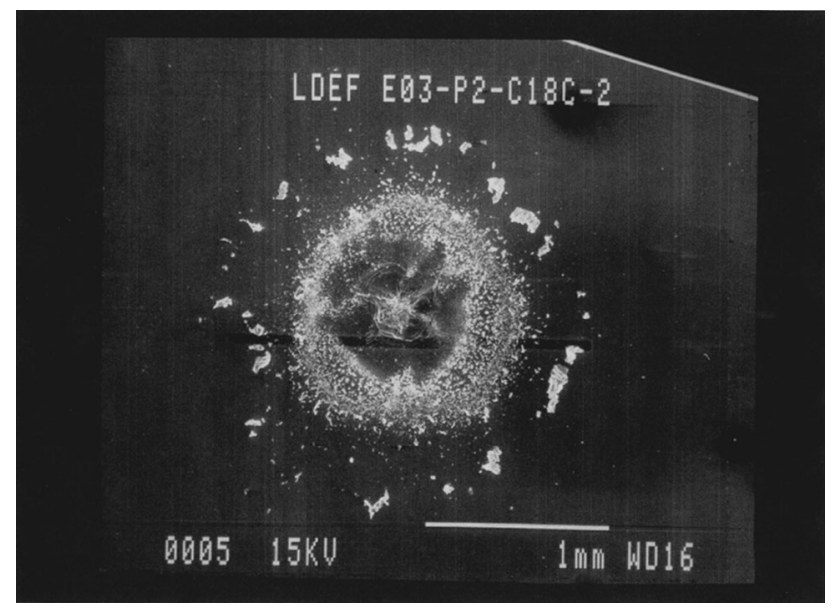

Fig. 1 SEM micrograph of an impact crater on a germanium surface caused by a cosmic dust particle. To clearly differentiate between ions generated from the carrier material and such of the impacted particle in the SIMS analysis, it is advantageous to use rather exotic and highly pure substrates, such as gold or germanium. The particles scattered around the impact crater are Ge particles and not remnants of the impacted cosmic particle which evaporated completely. Even extreme traces of its matter are detectable by SIMS in the stratosphere has to be discontinued for several months, because the volcanic dust clouds are dispersed quickly and thoroughly around the earth.

It goes without mentioning that during sample preparation and investigation, no additional contamination can be tolerated. Work has to be performed under strict cleanroom conditions and, due to the dust grain size, mostly under the microscope. Hence, particles are removed one by one from the collector surface and, subsequently, cleaned from the silicon oil. They are thereby viewed in the light microscope. Afterwards, they are characterized at higher magnification in the SEM. In the following, some typical particle morphologies of extraterrestrial particles are shown.

\section{Some results of the morphological characterization of cosmic dust particles}

The origin of cosmic dust was discussed in "Cosmic dust: an essential part of matter in the universe and the basis of the formation of our own solar system". Important conclusions derived from the isotopic compositions for, e.g., carbon and oxygen in cosmic particles can yield valuable information about their origin [5]. Here, only some typical morphologies are shown together with a listing of main constituents, as described in more detail in [14]. Figures 2, 3, 4 show the particles together with some descriptive remarks in the respective legends.

\section{Chondrites}

Chondrites are the most abundant class of meteorites with about $86 \%$ of the latter. Their name is derived from small

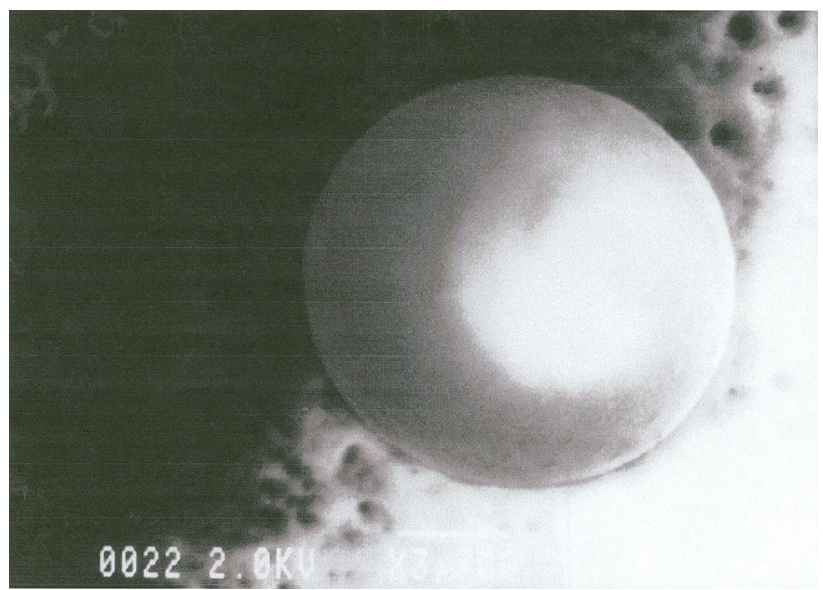

Fig. 2 Spherical particle. Main elemental composition: $\mathrm{Mg}$, Si, and $\mathrm{O}$ (traces $\mathrm{Ca}, \mathrm{Fe}$ ). The morphology of the particle indicates that it once was in a realm, where the temperature was higher than its melting temperature. Another possibility would be the emission from a melt. The particle diameter is $16 \mu \mathrm{m}$ [10] 


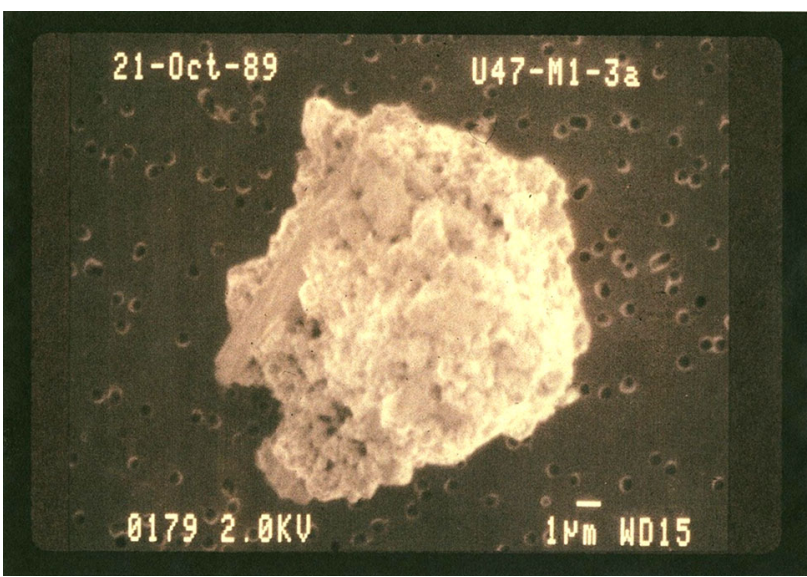

Fig. 3 This particle is a conglomerate of smaller particles. Main elemental components: $\mathrm{Mg}$ and $\mathrm{O}(\mathrm{N}, \mathrm{C}$, and $\mathrm{H})$

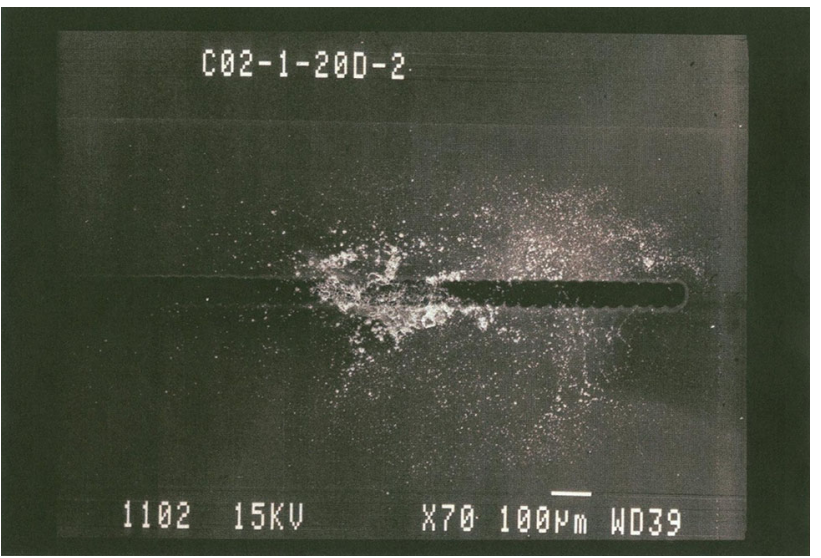

Fig. 4 Precipitate of an LDEF impact on germanium. The broad dark stripe is the trace of the ion beam with which the analysis was carried out

pellets of silicates which are called chondrules. They are $\mu \mathrm{m}$-sized and spheroidal and they were once molten droplets. They are imbedded in a matrix which is dominated by the minerals olivine, pyroxene, and plagioklas. Most of them contain metallic nickel-iron and iron-sulfide. Their respective contents vary greatly.

SIMS results on the composition of extraterrestrial particles yielded another interesting detail: many analyzed cosmic particles exhibited nearly the same composition as so-called the chondritic CAI-meteorites (Ca-Al-inclusions) which are characterized in Table 1 [6]. They consist of $\mathrm{Ca}-$ Al-silicates and oxides

Size distribution: most particles are smaller than $20 \mu \mathrm{m}$ and contain considerable amounts of aggregated sub- $\mu \mathrm{m}$ grains [7]. The data given in Table 1 are for the most abundant types of chondrites.

It is believed that the solar nebula from which our solar system developed 4.5 billion years ago had the same
Table 1 Main constituents for the most abundant types of chondrites and respective concentration ranges in $\% \mathrm{w} / \mathrm{w}$ as well as traces in $\mu \mathrm{g} / \mathrm{g}$ according to [6]

\begin{tabular}{ll}
\hline $\mathrm{SiO}_{2}$ & $22.8-40.4$ \\
$\mathrm{FeO}_{\text {total }}$ & $23.4-37.3$ \\
$\mathrm{MgO}$ & $15.6-25.4$ \\
$\mathrm{CaO}$ & $1.2-2.7$ \\
$\mathrm{Al}_{2} \mathrm{O}_{3}$ & $1.5-3.3$ \\
$\mathrm{H}_{2} \mathrm{O}$ & $0.6-17.9$ \\
$\mathrm{CO}_{2}$ & $0.3-11.7$ \\
$\mathrm{~S}$ & $2.0-5.8$ \\
$\mathrm{Ni}$ & $1.1-1.7$ \\
$\mathrm{P}_{2} \mathrm{O}_{5}$ & $<1.0$ \\
$\mathrm{~K}_{2} \mathrm{O}$ & $<1.0$ \\
$\mathrm{Na}_{2} \mathrm{O}$ & $<1.0$ \\
$\mathrm{TiO}_{2}$ & $0.07-0.16$ \\
\hline
\end{tabular}

All other metals and non-metals are in the $\mu \mathrm{g} / \mathrm{g}$ range: $\mathrm{Li}, \mathrm{Be}, \mathrm{B}, \mathrm{N}, \mathrm{F}$, $\mathrm{Cl}, \mathrm{Sc}, \mathrm{V}, \mathrm{Cr}, \mathrm{Co}, \mathrm{Cu}, \mathrm{Zn}, \mathrm{Ga}, \mathrm{Ge}, \mathrm{As}, \mathrm{Se}, \mathrm{Br}, \mathrm{Rb}, \mathrm{Sr}, \mathrm{Y}, \mathrm{Zr}, \mathrm{Nb}, \mathrm{Mo}$, $\mathrm{Ru}, \mathrm{Rh}, \mathrm{Pd}, \mathrm{Ag}, \mathrm{Cd}, \mathrm{In}, \mathrm{Sn}, \mathrm{Te}, \mathrm{Sb}, \mathrm{J}, \mathrm{Cs}, \mathrm{Ba}, \mathrm{La}, \mathrm{Ce}, \mathrm{Pr}, \mathrm{Nd}, \mathrm{Sm}, \mathrm{Eu}$, Gd, Tb, Dy, Ho, Er, Tm, Yb, Lu, Hf, Ta, W, Re, Os, Ir, Pt, Au, Hg, Tl, $\mathrm{Pb}, \mathrm{Bi}, \mathrm{Th}$, and $\mathrm{U}$

chondritic composition. Eventually, the planets and other bodies developed, the composition of which varies considerably and deviates from this original composition because of diverse chemical processes (so-called fractionations). However, material with chondritic composition is still found in some meteorites and many cosmic dust particles. This is an indication that these objects are of "primitive" nature, i.e., a very old and unchanged material [10].

\section{Carbonaceous chondrites}

These contain organic carbon in form of organic molecules as, e.g., amino acids or polycyclic aromatic carbohydrates together with water. This could be an indication that essential components for life may have arrived on the Earth by meteorites [6]. They are black and crumbly and the biggest piece came down to the Earth in Murchison, Victoria, Australia, in September 1969. It is part of a meteorite 4.5 billion years old [5].

\section{Low earth orbits (LEO) and their nature}

The altitude between 180 and $1000 \mathrm{~km}$ above the earth's surface is called low earth orbit(s) (LEO). It is the busiest traffic zone in near-Earth space. Nevertheless, the conditions in LEO are harsh. It is a region of intensive, highenergy UV radiation. The little oxygen still present from the earth's atmosphere is highly reactive atomic oxygen. It is also a region of high-temperature variations even up to 
$1500 \mathrm{~K}$. It is full of man-made space debris in addition to cosmic dust micro-meteorites, as will be discussed in more detail in "Large-particle space debris: mortal danger in near-Earth space" [10, 15, 17].

The next region toward free space is called medium earth orbit (MEO). It is the range from $1000 \mathrm{~km}$ above the earth's surface up to $20,000 \mathrm{~km}$. This is the range, in which GPS satellite and Galileo satellite are placed (GPS = geostationary positioning systems). The GPS satellite is at an altitude of exactly $35,786 \mathrm{~km}$ above the earth's surface, where it retains its position above the earth permanently. This is of great importance for many uses of satellites, especially in GPS technology [2].

\section{The International Space Station (ISS)}

The construction of the station started in 1998. It is presently the largest artificial object orbiting the Earth in a height of 300-400 km. The ISS needs 92 min for a complete passage around the earth. The necessary velocity for a stable orbit is $28,476 \mathrm{~km} / \mathrm{h}$ which is approximately the travelling speed of the ISS. It is powered by $120 \mathrm{~kW}$ solar cells with an area of $4500 \mathrm{~m}^{2}[18,19]$.

Each day, its altitude declines between 50 and $150 \mathrm{~m}$ due to friction with air molecules. Whenever a space ship docks on to the ISS, it is tenderly pushed up a bit to maintain its altitude. Only at an altitude of 1,000 km above the Earth is the air resistance low enough, so that a satellite does not loose altitude due to friction [4]. It will de-orbit in 150 years. The cost to date is around 150 billion USD.

\section{The former space station "MIR"}

The first space station MIR (Russian: peace, world) was launched by the former Soviet Union in 1986. It was, at that time, the largest artificial object in an orbit around the Earth. It was also the greatest success of the Soviet space technology together with the launch of the Sputnik in 1957 and the first space travel of Yuri Gagarin in 1961. However, since the installation of the ISS, the MIR experienced a great loss of interest and it was, therefore, abandoned: The controlled crash of the MIR took place in 2001 after 15 years in space with approximately 86,300 orbits around the Earth. Some parts sank in the Southern Pacific between Australia and Chile [20].

\section{A glimpse on transport costs to the ISS}

Supposedly, everybody has already seen the impressive start of a transport rocket to the ISS from Cape Canaveral in Florida. From this, it should become understandable that space travel is a very costly affair. This should be demonstrated by the costs for the transport of just $1 \mathrm{~kg}$
Table 2 Costs of the transport of one kg material from the Earth to the ISS [2]

\begin{tabular}{ll}
\hline Russian freighter "Progress" & ca. $13,000 €$ \\
US Space Shuttle (until 2011) & ca. $35,000 €$ \\
Japanese HTV (unmanned) & ca. $35,000 €$ \\
ATV (Automated Transfer Vehicle) of the ESA & ca. $43,000 €$ \\
Private space transporter & ca. $90,000 €$ \\
\hline
\end{tabular}

from the Earth to the ISS, see Table 2. It indicates that $1 \mathrm{~L}$ of drinking water in the ISS costs in the neighborhood of $20,000 €$. For further space travels, e.g., to Mars, costs will rise massively over the ones given in Table 1.

\section{The significance of material degradation of space exposed surfaces}

It has been mentioned earlier that particles are travelling in LEO with velocities of around $10 \mathrm{~km} / \mathrm{s}$. When they hit material surfaces, they almost completely evaporate due to their high impact velocity and cause the formation of a crater, which is up to one order of magnitude larger than the impacting particle. This turns out to be a serious problem for space technology, because the impact of a multitude of such particles will quickly deteriorate space exposed surfaces. The mean lifetime, e.g., of solar panels for generation of energy for satellites is, thus, seriously reduced $[14,21]$.

\section{The LDEF experiment}

This has alarmed the American National Aeronautics and Space Administration (NASA) to an extent that a respective materials degradation experiment was organized, the LDEF experiment (Long Duration Exposure Facility) [22]. The heart of this action was a large cylindrical satellite with a length of $9 \mathrm{~m}$ which is shown in Fig. 5.

This satellite was the size of a bus, and it was brought into an LEO at an altitude of $476 \mathrm{~km}$ in 1984 [22]. It contained more than 10,000 test material plates which were exposed to the rather unfriendly environment of the LEO for degradation studies. These surfaces were exposed to bombardment by micro-meteorites and near-Earth space debris of man-made origin which led to a deterioration of the plates' surfaces. The orbital period of LDEF is only 90 min long. Hence, the surface temperature of the LDEF assembly varies greatly. During its exposure to sun, intensive UV radiation is hitting the surface. This effect, combined with atomic oxygen (Atox), which is also present due to the last traces of the earth's atmosphere in this altitude, resulted in interesting corrosion and erosion phenomena [22]. The satellite was not retrieved after the 


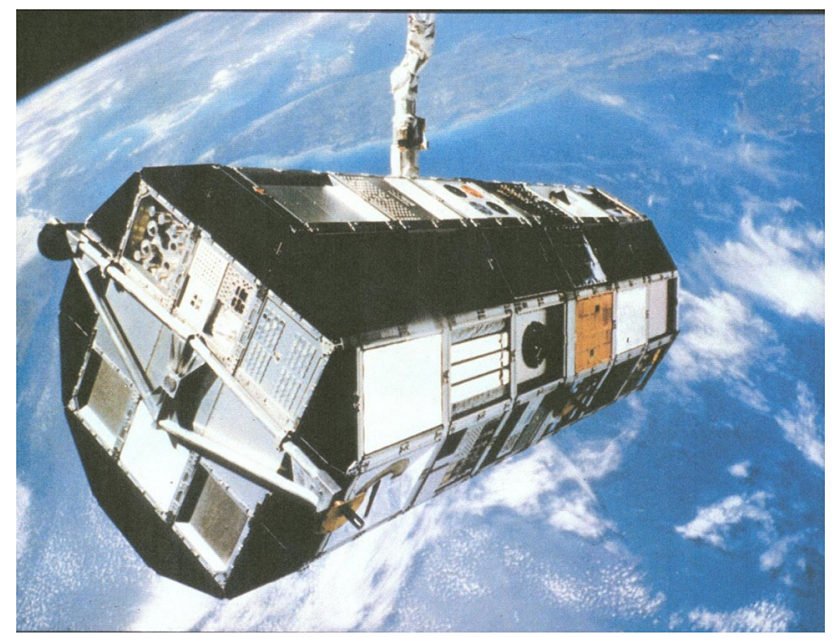

Fig. 5 View of the LDEF experiment exposed in LEO (Courtesy of NASA Langley Research Center). Clouds over the earth's surface are seen in the background

planned exposure time due to the Challenger disaster. Only in 1990 after 34,000 earth orbits in 2105 days, the LDEF experiment was retrieved in the last possible moment by the Space Shuttle, Fig. 6. It was taken into the shuttle in an altitude of only $333 \mathrm{~km}$ shortly before the satellite would have burned up in the upper atmosphere. However, due to its very long exposure time, corrosion and erosion phenomena were very pronounced, and a lot of interesting and alarming observations were made [22]. One of the most alarming finds was that more than $80 \%$ of all investigated particle impact craters by SIMS turned out to be caused by terrestrial (man-made) and not by cosmic particles. The highest percentage of these particles was $\mathrm{Al}_{2} \mathrm{O}_{3}$ particles stemming from solid-state rocket fuels. This was the reason why Russia finally changed over to liquid fuel systems.

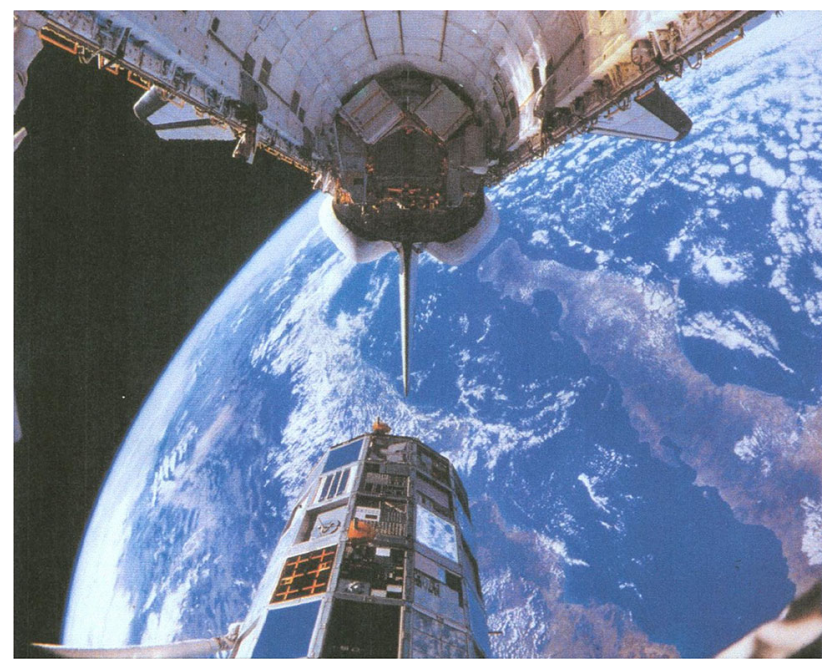

Fig. 6 Recovery of the LDEF experiment from LEO. The open space shuttle is ready to receive the LDEF cylinder
However, not only $\mathrm{Al}_{2} \mathrm{O}_{3}$ particles of terrestrial origin had been detected, titanium- and cadmium-rich particles were also registered. They originated from paints with which rocket surfaces had been painted. Particles of stainless steel, mineral particles, and silver solder had also been detected [22]. The geometry of the impact craters of particles allowed calculations of the velocity of impacting particles.

\section{The Hubble Space Telescope}

Figure 7 shows the famous Hubble Space Telescope (HST) [21] during the first servicing mission 1993 after the installation of the solar panels which power the assembly. These solar array wings have been replaced after almost 4 years in space. One of these wings was brought back to Earth, and a part of it was also investigated by our research group at $T U$ Darmstadt [14, 21]. It orbits the Earth in an altitude of $600 \mathrm{~km}$. It has detected 50 billion galaxies and astronomers are supposing, today, the existence of a total of 125 billion galaxies in the universe [21-24]. The telescope sees more clearly than ever. The HST is powered by solar cells which are mounted on two flexible solar array wings. These solar array wings have been replaced after almost 4 years in space. One of these solar array wings was brought back to Earth, while the other one was jettisoned. The retrieving of this solar array offered a unique possibility for the investigation of the conditions in the LEO. This wing was exposed to a permanent flux of micro particles. Since it was of interest whether these particles were

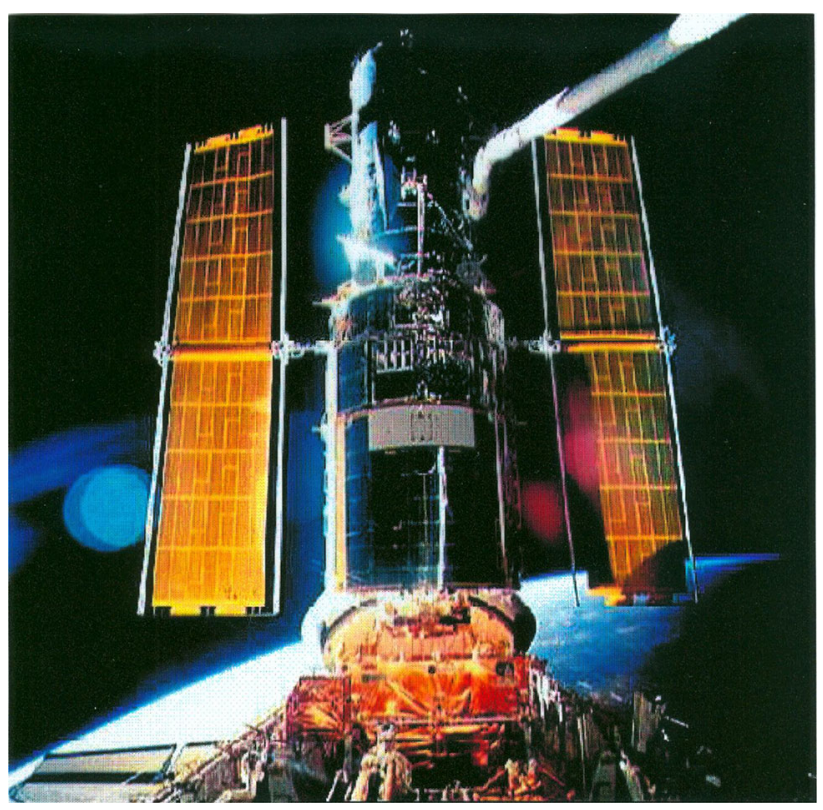

Fig. 7 View of the famous Hubble Space Telescope during the first servicing mission in December 1993 after the installation of the solar panels 

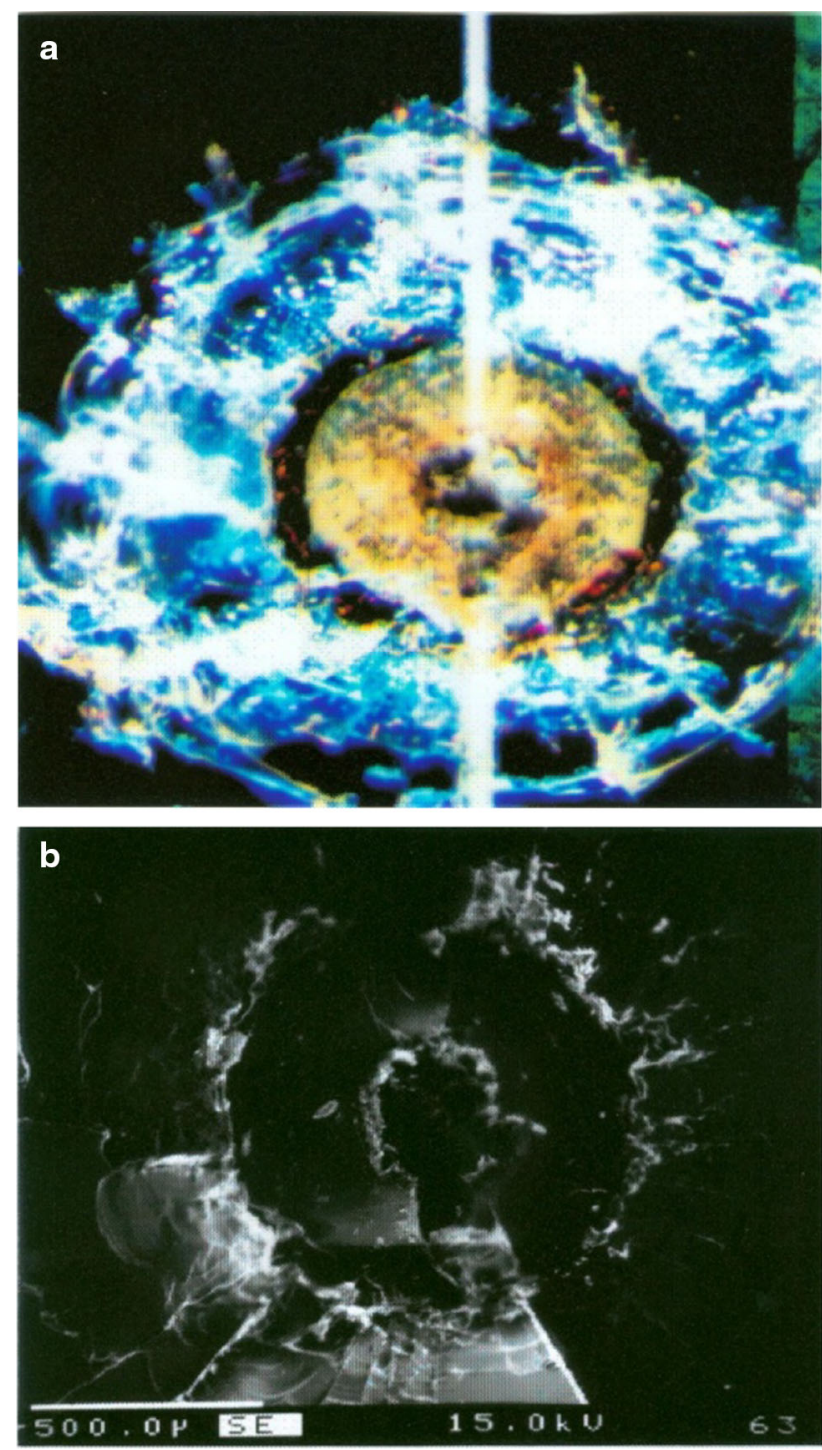

Fig. 8 Photo (a) and secondary electron image (b) (of a scanning electron microscope) of a particle impact on a solar cell panel of the Hubble Space Telescope

man-made debris or micro-meteorites, the European Research and Technology Centre (ESTEC) decided to disassemble two of the ten solar panel assemblies for further investigation, in which our group participated [25]. Figure $8 \mathrm{a}, \mathrm{b}$ shows a photo and a secondary electron image (SEM) of a particle impact on a solar cell panel of the HST [25].

\section{Large-particle space debris: mortal danger in near-Earth space}

However, there is more than cosmic dust and asteroids to worry about in LEO: There is eminent danger of collision of space vehicles with much bigger "particles" of space debris. The reason is a rising number of debris items with more than $10 \mathrm{~cm}$ diameter, mainly rocket parts, diverse metal parts like screws or lost wrenches, further astronauts' gloves, and even frozen faeces from the toilets of space vessels. It all started with 33 military surveillance satellites from the former Soviet Union which had been blown up at the end of their lifetime. Their parts circle the Earth until they lose altitude down to some $90 \mathrm{~km}$ when they hopefully burn up totally. Prior, these parts move with about $28,000 \mathrm{~km} / \mathrm{h}$ in the LEO domain and are only very gradually slowed down by the very thin atmosphere of the earth at these altitudes. It is very fortunate that up to now, there has been no catastrophic collisions with space vehicles, since it is estimated that about $3000 \mathrm{t}$ of debris circle the earth in LEO below approximately $2000 \mathrm{~km}$ altitude [26]. The highest respective density of such parts exists between 800 and $1000 \mathrm{~km}$ above the earth's surface. Their number is about 200,000 . Furthermore, another 100,000 parts with diameters between 1 and $10 \mathrm{~cm}$ and another billion parts with diameters below $1 \mathrm{~cm}$ complete this symphony of danger for space vehicles and installations in LEO. To make things worse, the Soviet satellites had been equipped with small atomic reactors as energy source. Hence, radioactive parts are also travelling in LEO as metallic clouds together with other debris from these explosions. Hence, LEO has become something like an international waste disposal.

\section{Space debris mitigation measures}

No wonder that this has become a primary source of danger for space flights within the LEO area. NASA, therefore, has installed a watch center which has registered larger pieces of space debris in something like a space-emergency map to save space shuttles and rockets from collisions with scrap. The European Space Operations Centre (ESOC) in Darmstadt (Germany) has also installed a Space Debris Working Group with the same responsibility. There are even regular conferences on Space Debris organized by the European Space Agency (ESA).

Even, a Space Debris Mitigation Handbook has been issued by the ESA [27]. The following quote outlines its main aims:

"The implementation of debris mitigation measures, in particular the de-orbiting of spacecraft and upper stages, is shown to reduce the debris growth to an acceptable level within a few decades. The risk on ground due to re-entering space objects, its assessment, and its control is also analyzed. For on-orbit systems, collision risk reduction by avoidance manoeuvres and passive protection by shielding are outlined. ESA's handbook also compares recommended debris mitigation and risk reduction practices proposed by several other space agencies" [27]. 


\section{More huge particles: the asteroid belt}

The nature, structure, and nomenclature of asteroids and comets have been described in detail in $[2,28]$. The main number of asteroids is found in the Belt of Asteroids which is situated between the orbits of Mars and Jupiter. Some of these asteroids exhibit pronounced elliptic orbits around the sun. These were caused by interactions with great masses, e.g., of Jupiter, if they come near to it [24]. Such asteroids might also cross the orbits of the Earth or Mars and very infrequently lead to respective collisions which, consequently, cause catastrophic short term climate changes due to the huge amounts of dust transported to the upper regions of the earth's atmosphere. Several asteroids have been inspected by space ships of Europe, the USA, Russia, and Japan [28]. The most recent fascinating visit is the Rosetta Mission to the asteroid 67P/ChuryumovGerasimenko, shortly called Tshuri. Previously various missions had taken place to the comet Halley [28] launched by Russia (two VEGA missions), Japan (also two missions), the USA (Probe called ICE), and one European mission (called Giotto) [28].

\section{Some notes on the Rosetta Mission}

\section{Start: March 02, 2004}

Landing on Tshuri: November 12, 2014

This is the most ambitious mission of the European Space Agency (ESA). The aim is the scientific inspection of the previously mentioned comet Tshuri. From the first respective idea to the advent of the space ship at the comet, it took 25 years! Numerous scientists from 17 nations have participated in this extraordinary project which is described in detail in [28]. The asteroid has a size of only $4 \times 3.5 \mathrm{~km}$. Consequently its gravity pull is minute: $100 \mathrm{~kg}$ on Erath weigh only $1 \mathrm{~g}$ on Tshuri [29, p. 205]. Hence, Philae had special fastening mechanisms to be fixed to Tshuri upon landing. Philae performed a great leap of $455 \mathrm{~m}$ in height after touchdown. Its final position on Tshuri is not a fortunate one being in the shade of great ice walls. Hence, the solar panels cannot produce energy any more.

A good description of what happened in detail at the Philae landing and afterwards is given in [28-30].

It can be concluded that a lot of interesting information had been collected in the course of this landing procedure. Total costs of the Rosetta mission are exceeding one billion Euros.

Very unexpectedly, Philae contacted the ground control of the ESA again and sent 300 packages of data on June 13, 2015. Philae's temperature was reported to be $-35^{\circ} \mathrm{C}$. This contact in June was presumably the very last one from the Lander Philae to the Earth [30]. Furthermore, since Tshuri reached its point nearest to the sun on August 8, 2015, the temperature of Philae sinks considerably, since then.

The mission is named after the Rosetta stone, a slab of volcanic basalt found near the Egyptian town of Rashid (Rosetta) in 1799. The stone revolutionized our understanding of the past. By comparing the three carved inscriptions on the stone (written in two forms of Egyptian and Greek), historians were able to decipher the mysterious hieroglyphics-the written language of ancient Egypt. As a result of this, breakthrough scholars were able to piece together the history of a lost culture.

In analogy to this, the Rosetta Mission should be a very valuable contribution to shed light on our cosmic past [28].

\section{The two most recent incidents with asteroids and the Earth $[4,29]$}

\section{The Tunguska incident in 1908}

\section{The Chelyabinsk incident in $\mathbf{2 0 1 3}$}

The most important respective data are summarized in Tables 3 and 4. It is interesting to note that in both cases, the asteroids exploded high above the ground, in an altitude of 8 and $30 \mathrm{~km}$, respectively.

\section{The speed of light and the magnificence of the universe}

The speed of light in vacuum amounts to exactly $299,792.458 \mathrm{~km} / \mathrm{s}$, i.e., approximately almost $300.000 \mathrm{~km} /$ $\mathrm{s}$. In one nanosecond $\left(1 \times 10^{-9} \mathrm{~s}\right)$, it moves $30 \mathrm{~cm}$ which is the length of an A4 sheet of paper. Hence, the light of the moon reaches us in $1.3 \mathrm{~s}$, the light of the sun in $8 \mathrm{~min}$. All photons (light particles) move with the same speed irrespective of their wavelength [31]. No object with mass can move faster according to the following equation [32]:

Table 3 Tunguska Incident [4] Date: June 30, 1908

The incident was registered worldwide by seismographs

The asteroid was about $30-80 \mathrm{~m}$ in diameter. It exploded in a height of ca. $8 \mathrm{~km}$. All trees in an area of $2000 \mathrm{~km}^{2}$ were brought down (ca. 60 millions). Tunguska is a river system in western Siberia. The area is uninhabited

The probably greatest impact of an asteroid happened 65 million years ago in Mexico. It caused the extinction of the dinosaurs. The diameter of this asteroid was about $10 \mathrm{~km}$. It caused the large Chicxulub crater in the sea near the coast of Mexico. Interesting phenomenon: a layer of iridium (transition metal of the platinum group, atomic number: 77 , density: $22.56 \mathrm{~g} / \mathrm{cm}^{3}$, melting point: $2446{ }^{\circ} \mathrm{C}$ ) had been deposited in a large area by this impact 
Table 4 Chelyabinsk Incident [29] Date: Feb 15, 2013

Diameter of the asteroid: $19 \mathrm{~m}$ Weight: $12,000 \mathrm{t}$
Velocity: $19 \mathrm{~km} / \mathrm{s}$
Explosion in $30 \mathrm{~km}$ above ground in a so-called "Airburst"
Energy freed by the explosion: ca. $500 \mathrm{kt}$ TNT (TNT is the
abbreviation for trinitrotoluene). For comparison: The atomic
bomb of Hiroshima developed about $12.5 \mathrm{kt}$ TNT. This means
that the Chelyabinsk explosion was about 40 times stronger than
the Hiroshima bomb. If the path of the asteroid would have been
more perpendicular, Chelyabinsk would not exist anymore

$E_{\mathrm{kin}}=m_{0} \cdot c^{2}\left(\frac{1}{\sqrt{1-\frac{v^{2}}{c^{2}}}}-1\right)$,

symbols: $m_{0}$ mass of a particle with low or no velocity, $v$ speed of a moving particle, $c$ speed of light, $E_{\text {kin }}$ kinetic energy of a particle at $v \ll c$

$E_{\text {kin }}=\frac{m \cdot v^{2}}{2}$.

Particles gain weight when they move with very high speed (nearing the speed of light).

At $v \rightarrow c: m \rightarrow \infty$.

Due to the vast dimensions of the universe, the so-called light-year had been introduced in astronomy. It is the almost unimaginable distance the light travels in 1 year [31]:

$9,460,730,472,581 \mathrm{~km}$, i.e., approximately $9.5 \times 10^{12}$ $\mathrm{km}$. Another measure frequently used in astronomy is the astronomical unit (AU): It is the distance between the Sun and the Earth which is about 150 million $\mathrm{km}$. Furthermore, the most distant objects in the presently known universe are some quasars which are about 14 billion light years away [23]. The diameter of the Milky Way (our galaxy) measures 100,000 light-years. The nearest star, Proxima Centauri, is about 4.24 light-years away from us [31], a distance which will most likely never be overcome by man.

\section{Manned space travel even to our nearest planets is very dangerous and costly}

Since we have just seen that the distances in the universe are so unimaginably great and space travel is a very costly affair, it can be concluded that manned space travel even to our neighboring planets is a rather dangerous enterprise. It has been argued that a trip to Mars would be principally possible and it is in the planning stage. The situation for a manned trip to our next inner neighbor planet, the Venus, is worse: Venus exhibits an average surface temperature around $470{ }^{\circ} \mathrm{C}$ ! Its atmosphere consists of $\mathrm{CO}_{2}$ and little $\mathrm{SO}_{2}[28]$.
It is very questionable whether such an effort is reasonable-apart from the dangers for the respective space vehicle to be hit by meteorites or other catastrophes [23]. Intensive gamma radiation is another possibly deadly danger in space travel [29], as well as exposure to highly energetic particles.

\section{Conclusion}

It is not surprising that the investigation of interplanetary dust has developed to a most important scientific discipline in the space sciences. Dust is an essential component throughout space. It constitutes a considerable part of the total matter of our universe. Consequently, material degradation by dust particles or "micro-meteorites" is one of the common phenomena space exposed surfaces have to cope with. Hence, space stations and space vehicles may be seriously eroded by cosmic dust hitting these surfaces with great velocity. This has been extensively studied by secondary ion mass spectrometry $[14,25]$. This is the key instrumentation for cosmic dust analysis and dust eroded surfaces in combination with scanning electron microscopy. The significance of material degradation of space exposed surfaces has been extensively studied by a "Long Duration Exposure Facility"-experiment managed by NASA (cf. "The LDEF experiment").

Furthermore, it is a remarkable development that an initial project of pure basic science-the collection and study of cosmic dust-became unexpectedly the solution to an ardent problem of space technology: What effect does the impact of cosmic dust particles exert on space exposed surfaces of materials in complex space installations? This has been demonstrated shortly. Hence, space stations and satellites serve many technological systems, such as GPS and many other important remote sensing stations today. The latter give valuable information, e.g., on the effects of climate change, deforestation, or on the future development of the Earth's climate. These stations may have a shorter lifetime than anticipated due to surface damage by the bombardment with cosmic particles. It is also an interesting result of this young scientific discipline that a part of the particles which come into the range of the gravity pull of our earth will eventually be trapped by it. Hence, our planet is collecting cosmic dust daily in a quantity of several tonnes. This leads to the conclusion that cosmic dust is not as exotic a material, as we usually think. And every time our window sills or our book shelves are cleaned, we can be sure to dust away also some particles from Deep Space! I would like to close with what I think is an important consideration: The universe in certain areas is beautiful. This is convincingly shown in a great article in the April 2015 issue of the National Geographic [33] and in other 
publications [23, 24]. Ultimately, since our Earth has been formed from cosmic dust, we can say that we, too, are children of cosmic dust!

Acknowledgments The author wants to thank Dr. Hans Joachim Lunk, Towanda, PA, USA, and Prof. Dr Stephan Weinbruch, Institut für Angewandte Geowissenschaften der TU Darmstadt, Germany, for their valuable suggestions in the course of the preparation of this paper.

\section{References}

1. Köberl C (1998) Impact. Gefahr aus dem All (Impact. Danger from the Universe). Verlag Va Bene, Wien-Klosterneuburg. ISBN 3-85167-074-4

2. Freistetter F (2015) Asteroid now-Warum die Zukunft der Menschheit in den Sternen liegt, Chapter 1. Carl Hanser Verlag, Munich

3. Plane JMC (2012) Cosmic dust in the earth's atmosphere. J Atmos Sol-Terr Phys 41:6507-6518

4. Freistetter F (2013) Der Komet im Cocktailglas (The comet in the cocktail glass), vol 65. Carl Hanser Verlag, Munich

5. Bührke Th (2009) Sternenstaub auf Erden (Stardust on earth). Bild der Wissenschaft 12:41-45

6. Markl G (2008) Minerale und Gesteine - Mineralogie - Petrologie - Geochemie (Minerals and rocks-mineralogy-petrologygeochemistry). Spektrum Akademischer Verlag, Heidelberg

7. Grün F, Gustafson BAS, Dermott SF, Fechtig H (eds) (2001) Interplanetary dust. Springer, Berlin

8. Millar TJ, Williams DA (eds) (1993) Dust and chemistry in astronomy. The graduate series in astronomy. Institute of Physics Publishing, Philadelphia

9. Allamandola L, Thielens A (eds) (1989) Interstellar dust. Kluver, Dordrecht

10. Stadermann FJ (1992) Cosmic dust particles-samples from the original solar nebula (in German). Phys Unserer Zeit 23:197-203

11. Stadermann FJ, Hoppe P, Floss C et al (2008) Stardust in stardust - the $\mathrm{C}, \mathrm{N}$, and $\mathrm{O}$ isotopic compositions of Wild 2 cometary matter in Al foil impacts. Meteorit Planet Sci 43(1-2):299-313

12. Goldstein JI, Newbury DE, Echlin P, Joy DC, Fiori Lifshin E (1992) Scanning electron microscopy and X-ray microanalysis, 2nd edn. Plenum Press, New York

13. Bernatowicz TJ, Walker RM (1997) Ancient stardust in the laboratory. Phys Today 50:26-32
14. Ortner HM, Stadermann FJ (2009) Degradation of space exposed surfaces by hypervelocity dust bombardment, and refractory metals for space. Int J Refract Met Hard Mater 2:949-956

15. Stadermann FJ (1990) Ph.D.-thesis: measurement of isotopeand element-frequencies in single interplanetary dust particles by secondary ion mass spectrometry (in German), University of Heidelberg

16. Schuhmacher M, Rasser B, De Chambost B, Hillion F, Mortz Th, Migeon HN (1999) Recent instrumental developments in magnetic sector SIMS. Fresenius J Anal Chem 365:12-18

17. Murr LE, Kinard WH (1993) Effects of low earth orbit. Am Sci $81: 152-165$

18. https://www.nasa.gov/mission_pages/station/main/index.html

19. https://en.wikipedia.org/wiki/International_Space_Station

20. https://en.wikipedia.org/wiki/Mir

21. Ortner HM (2010) Degradation of space exposed surfaces by hypervelocity dust bombardment—example: solar cell samples. In: Ochieng RM (ed) Solar collectors and panels, theory and applications. Sciyo, Croatia, pp 97-110

22. Mandeville JC (1991) Study of cosmic dust particles on board LDEF: The Frecopa experiment. Adv Space Res 11(12):12101-12107

23. Smith BA, Ressmeyer RH (1994) New eyes on the Universe. Natl Geogr Mag 185:2-41

24. Carroll CH (2010) Hubble renewed. Natl Geogr Mag 2010:123-129

25. Heiss CH, Stadermann FJ (1997) Chemical analysis of hypervelocity impacts on the solar cells of the Hubble Space Telescope with EPMA-EDX and SIMS. Adv Space Res 19:257-260

26. Fletcher K (2013) Space debris, ESA communications production BR-309. ISBN 978-92-9221-059-5

27. Klinkrad H, Beltrami P, Hauptmann S, Martin C, Sdunnus H, Stokes H, Walker R, Wilkinson J (2002) The ESA space debris mitigation handbook. Elsevier, Amsterdam

28. Möhlmann D, St Ulamec (2014) Space vehicle Rosetta: The adventurous trip to an unknown comet. Franckh-Kosmos Verlags GmbH und Co. KG, Stuttgart (in German)

29. Oberhummer H, Puntigam M, Gruber W (2015) The Universe is a shitty place [in German]. Hansa, Munich

30. Dambeck T (2015) Living sign of Philae. Bild der Wissenschaft 12:46-48 (in German)

31. Hart-Davis A (2012) The book about the time. Primus Verlag, Darmstadt (in German)

32. Finkelnburg W (1967) An introduction to atomic physics. Springer, Berlin (in German)

33. Ferris T (2015) Hubble's Greatest Hits, Natl Geogr 62-75 